\title{
ESTUDO COMPARATIVO POR RESSONÂNCIA MAGNÉTICA DE PÚBIS ENTRE ATLETAS E SEDENTÁRIOS ASSINTOMÁTICOS
}

\author{
COMPARATIVE STUDY BETWEEN THE PUBIS OF \\ ASYMPTOMATIC ATHLETES AND NON-ATHLETES WITH MRI
}

Rodrigo Castelo Branco', César Rubens da Costa Fontenelle², Leandro Marques Miranda', Yonder Archanjo Ching San Junior ${ }^{1}$, Evandro Miguelote Vianna ${ }^{3}$

\section{RESUMO}

Objetivo: Comparar os achados na ressonância magnética do púbis de atletas profissionais de futebol, sem histórico ou clínica de pubalgia, com sedentários também assintomáticos, determinando a prevalência de alterações compatíveis com sobrecarga púbica. Métodos: Dezenove atletas profissionais de futebol, sem queixas álgicas na região púbica, e 17 sedentários, também assintomáticos, foram submetidos à ressonância magnética do púbis. Os resultados dos exames foram analisados quanto à presença de alterações degenerativas, edema medular ósseo e tendinopatia, comparando ambos os grupos estudados. Resultados: Foi encontrada alta prevalência de edema ósseo e tendinopatia, bem como alterações degenerativas da sínfise púbica no grupo de atletas, encontrando-se valores maiores de odds ratio e risco relativo, com significância estatística na população estudada. Conclusão: Atletas profissionais de futebol apresentam maior risco de desenvolver alterações na região púbica, evidenciadas na ressonância magnética, se comparados a indivíduos sedentários. Estes achados não são obrigatoriamente causa de pubalgia, estando provavelmente relacionados a esforço intenso.

Descriotores - Pubalgia; Atletas; Osteíte Púbica; Ressonância Magnética; Púbis; Jogadores de Futebol

\section{ABSTRACT}

Objective: To compare the magnetic resonance imaging findings of the pubis of professional soccer players, without history of or clinical groin pain, and non-athletes, also without symptoms, determining the prevalence of changes compatible with pubic overload. Methods: Nineteen professional soccer players without complaints of groin pain and seventeen nonathletes, also asymptomatic, underwent pubic magnetic resonance images. Exam findings were analyzed for the presence of degenerative changes, medullar edema and tendinopathy, comparing both groups. Results: High prevalence of bone edema, tendinopathy and degenerative findings in the pubic symphysis was seen in athletes, with statistically significant higher odds ratios and relative risk for the population studied. Conclusion: Professional soccer players are at a higher risk for developing changes in the pubic region, evidenced in magnetic resonance images, when compared to non-athletes. Those findings are not necessarily related to groin pain, and are probably related to intense stress.

Keywords - Pubalgia; Athletes; Osteitis; Magnetic Ressonance; Pubis; Soccer Players

\section{INTRODUÇÃO}

A pubalgia é uma patologia relativamente comum, acometendo $2 \%$ a $7 \%$ dos atletas profissionais de diversas modalidades ${ }^{(1-3)}$. Em praticantes de futebol, a prevalência pode atingir 58\%(4). A dor crônica e inca- pacitante em região inguinal pode levar ao afastamento do atleta do nível competitivo do esporte praticado, gerando assim um grande impacto socioeconômico ${ }^{(1,3,5,6)}$. Associada a outras patologias do quadril, como impacto femoroacetabular, lesão labral e patologias articulares

\footnotetext{
1 - Médico Residente do Serviço de Ortopedia e Traumatologia do Hospital Universitário Clementino Fraga Filho (HUCFF - UFRJ).

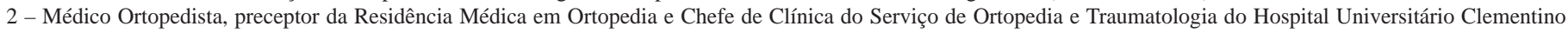
Fraga Filho (HUCFF - UFRJ).

3 - Médico Radiologista, Membro do Colégio Brasileiro de Radiologia e Médico Radiologista da Clínica Radiológica Multimagem (RJ).
}

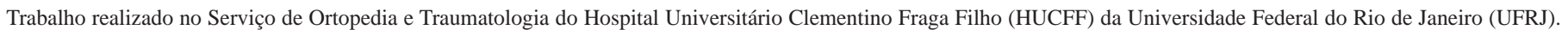

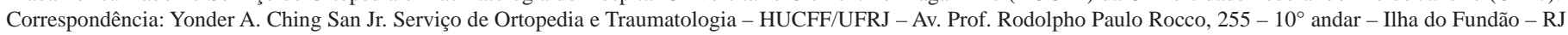
- CEP 21941-913. E-mail: yonder@cremerj.org.br ou yondersanjr@gmail.com

Trabalho recebido para publicação: 16/01/10, aceito para publicação: 26/04/10. 
do quadril, a dor no quadril é uma importante causa de afastamento do atleta de suas atividades competitivas.

A etiologia da pubalgia é variada, incluindo osteíte púbica, tendinopatia dos adutores, principalmente adutor longo, lesões do músculo reto abdominal, hérnia do esporte $\mathrm{e}^{(1,2,4,7,8)}$. Outras patologias como contusão, lesão ou tendinite dos músculos grácil, iliopsoas ou reto femoral, lesão labral, alterações degenerativas do quadril ou sínfise púbica, miosite ossificante, fraturas por estresse, epifisite, fraturas por avulsão, radiculopatia lombar, neoplasias, espondiloartropatias, além de distúrbios urológicos ou ginecológicos completam o diagnóstico diferencial ${ }^{(6,9,10)}$.

O diagnóstico é essencialmente clínico e se baseia na história compatível e no exame físico. Como métodos complementares, são utilizadas a ultrassonografia, a cintilografia e a ressonância nuclear magnética, sendo esta última o padrão ouro, com maior sensibilidade, especificidade e acurácia ${ }^{(1,2,5,9-12)}$.

A pubalgia é caracterizada por presença de dor insidiosa em região púbica e inguinal profunda, que piora com esforços e durante a marcha. Eventualmente se irradia para as regiões perineal, medial da coxa e reto abdominal. É mais comum o acometimento unilateral, porém existem diversos relatos de bilateralidade ${ }^{(1-5,9)}$. Histórico de atividades desportivas intensas que exigem aceleração brusca, chute, alternância rápida de apoio monopodal, mudança brusca de direção e movimento circular do tronco estão geralmente presentes ${ }^{(5,7,8,13)}$, sendo causa comum de afastamento de atletas de alto nível.

Períodos de melhora e exacerbação podem ser relatados, relacionando-se à intensidade de treinamentos e competições. No exame físico, pode-se observar dor à adução resistida do quadril, bem como hipersensibilidade na sínfise púbica e na região insercional dos músculos reto abdominal e adutor longo ${ }^{(3,4,8)}$.

A ressonância nuclear magnética do púbis é o exame complementar de escolha para o diagnóstico destas lesões $^{(10)}$. Embora a tomografia computadorizada evidencie lesões degenerativas ósseas precoces, a ressonância magnética apresenta maior sensibilidade uma vez que permite identificar lesões tendinosas e musculares precocemente. Os achados de edema ósseo na sínfise púbica, alterações degenerativas, líquido intra-articular ou lesão no tendão dos músculos adutor e reto abdominal são comumente relacionados à patologia ${ }^{(10,11,12)}$. Alguns autores, ao analisar atletas assintomáticos, encontraram as mesmas alterações em número significa- tivo, reduzindo assim a acurácia do exame. Segundo eles, até dois terços dos atletas assintomáticos possuem alterações sugestivas de patologia púbica. Considerada como tendo sensibilidade de $98 \%$ e especificidade de 100\% no diagnóstico da pubalgia, a ressonância nuclear magnética mostrou-se pouco sensível, com alto índice de falso positivo ${ }^{(10,14-16)}$. Este dado sugere que, embora o atleta apresente lesões consideradas sugestivas de pubalgia, não houve repercussão clínica no momento do estudo, mostrando assim que as alterações encontradas nas imagens traduzem o esforço excessivo e não diagnosticam a patologia. Nossa hipótese é que as alterações na ressonância magnética são mais frequentes em atletas, não sendo necessariamente causa de pubalgia.

\section{MATERIAIS E MÉTODOS}

Foram elegíveis para o estudo 26 atletas (todo o elenco) de uma equipe profissional de futebol da primeira divisão do Estado do Rio de Janeiro, em ritmo de competição. A equipe encontrava-se disputando o campeonato estadual, realizando uma competição semanal e cinco treinos; destes, três reproduziam o gesto desportivo. As imagens foram realizadas no meio da temporada, por ocasião das oitavas de final do campeonato. Foram excluídos três atletas devido ao quadro clínico prévio sugestivo, tendo o diagnóstico prévio de osteíte púbica tratada conservadoramente; três que não concordaram em ser submetidos ao exame, embora fossem assintomáticos; e um que estava afastado das atividades de treino há dois meses por quadro álgico no quadril, sugerindo patologia púbica. Restaram 19 atletas, todos submetidos à ressonância magnética do púbis. Nenhum destes apresentava patologia prévia no quadril e não referiam queixa álgica púbica ou femoroacetabular. O tempo médio de atividade profissional era de 54 meses, variando de 18 a 96 meses.

Como controle, 17 indivíduos do sexo masculino assintomáticos, sem histórico de dor inguinal, não praticantes de atividade esportiva (sedentários), com idades entre 23 e 38 anos, foram submetidos ao mesmo exame. A prática de atividade esportiva regular em algum período prévio ou alguma atividade ocasional nos últimos seis meses foi considerada critério de exclusão. A opção por este grupo de indivíduos, pareados por sexo e idade, deveu-se à menor probabilidade que estes indivíduos tenham sido submetidos a estresse púbico nos últimos meses. Um grupo constituído de atletas amadores poderia levar a resultados 
pouco confiáveis uma vez que o grau de atividade do atleta não seria controlado.

A idade dos atletas estudados variou de 18 a 31 anos, com média de 22,05 anos e mediana 22. Os sedentários apresentaram idade entre 23 e 38 anos, com média de 28,56 anos e mediana 28 anos. Os grupos se mostraram equivalentes, com $p$-valor de 0,71 .

Ambos os grupos, atletas e sedentários, foram submetidos ao mesmo protocolo de ressonância nuclear magnética. Foram obtidas imagens panorâmicas da bacia em T1 e STIR no plano coronal com cortes de $5 \mathrm{~mm}$ de espessura, FOV (field of view) de 42cm e imagens localizadas específicas do púbis em densidade protônica com supressão de gordura FSE (fast spin echo), com cortes de 3mm nos planos sagital e coronal oblíquo, TR 2450 e TE 37. Todos os exames foram gerados no mesmo aparelho (General Eletric ${ }^{\circledR} 1,5 \mathrm{~T}$ ).

Foram procuradas alterações degenerativas, caracterizadas por osteófitos, irregularidade da cortical e protrusão posterossuperior do disco articular. Além disso, sinal sugestivo de osteíte púbica (edema ósseo), lesão miotendínea nos músculos reto abdominal, adutor longo e adutor curto, caracterizada por lesão da aponeurose, ruptura completa e tendinose também foram pesquisados ${ }^{(3,5)}$.

Dois radiologistas experientes analisaram independentemente todas as imagens e emitiram laudos a respeito de alterações compatíveis com causas de pubalgia. $\mathrm{O}$ primeiro radiologista analisou as imagens obtidas de todos os atletas e do grupo controle, sendo as imagens e laudos revisados pelo radiologista sênior. Ambos os radiologistas desconheciam a natureza do paciente examinado (atleta ou sedentário).

Os resultados foram analisados estatisticamente, sendo considerado significativo $p<0,05$. Os dados foram analisados nos programas EPInfo 6.0 e Meta-DiSc v.1.4 pelo teste Kolmogorov-Smirnov e revisados por um profissional matemático-estatístico.

\section{RESULTADOS}

Dezoito atletas $(94,73 \%)$ apresentaram sinais sugestivos de alterações degenerativas como osteófitos, irregularidade da cortical e protrusão posterossuperior do disco articular (Figura 1), enquanto apenas um não atleta $(6,25 \%)$ teve imagem compatível com tal achado, com $p$-valor de 0,018 . O risco relativo (RR) calculado foi de 15,16 e a razão de chances (odds ratio ou OR) foi de 28,8 (Tabelas 1 e 2).

Edema ósseo representando osteíte púbica (Figura 2) foi observado em seis atletas (31,57\%), porém tal alteração foi vista em apenas um sedentário (6,25\%), com $p$-valor de 0,001 . O RR foi de 5,26 e o OR de 7,38 (Tabelas 1 e 2).

Alterações encontradas nos músculos ou tendões, sugerindo degeneração ou ruptura de adutores ou reto abdominal, foram encontradas em cinco atletas (26,31\%) e em um sedentário (6,25\%), com p-valor de 0,04. O risco relativo foi de 4,21 e o OR de 5,71.

\section{DISCUSSÃO}

A pubalgia é muito comum em atletas e, em nosso meio, particularmente em jogadores de futebol. Devido à aceleração e desaceleração, mudança brusca de direção e chutes repetitivos, os praticantes deste esporte têm maior probabilidade de apresentar dor na região inguinal. A etiologia é variada, incluindo osteíte púbica, tendinopatias do reto abdominal e adutor longo, hérnia, dentre outras ${ }^{(1-8,14,16)}$.

A ressonância magnética é considerada o padrão ouro para diagnosticar alterações dessa natureza presentes no púbis. Edema ósseo, derrame articular na sínfise púbica e lesões musculotendíneas são achados frequentes, além de alterações degenerativas.

Em estudos recentes, as mesmas alterações descritas nos pacientes com queixas álgicas são encontradas em
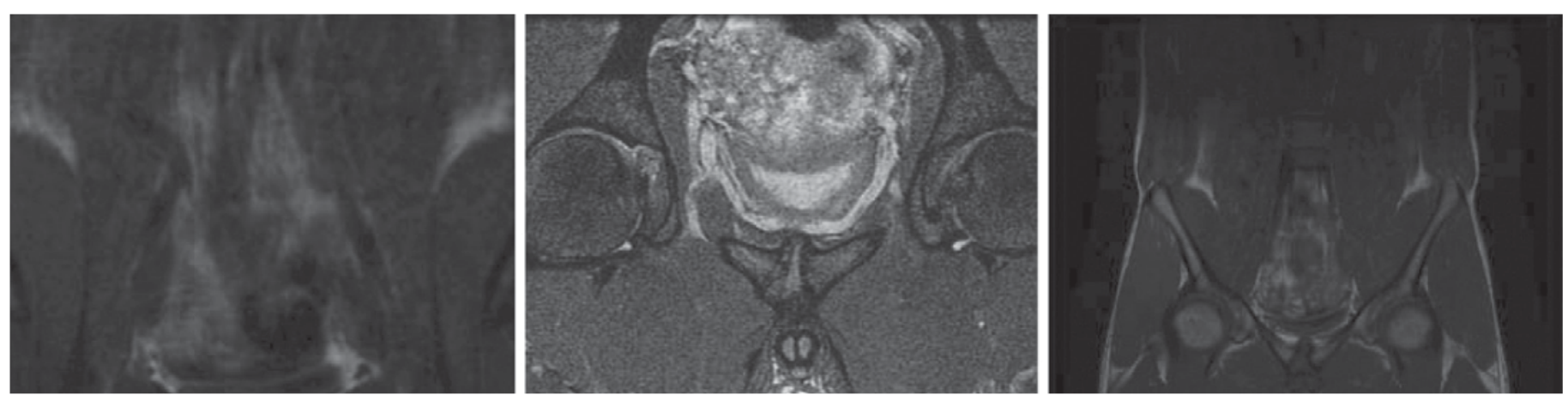

Figura 1 - Ressonância nuclear magnética de púbis de um jogador de futebol profissional mostrando alterações degenerativas na sínfise púbica, como osteófitos, irregularidade da superfície articular e protrusão discal. 


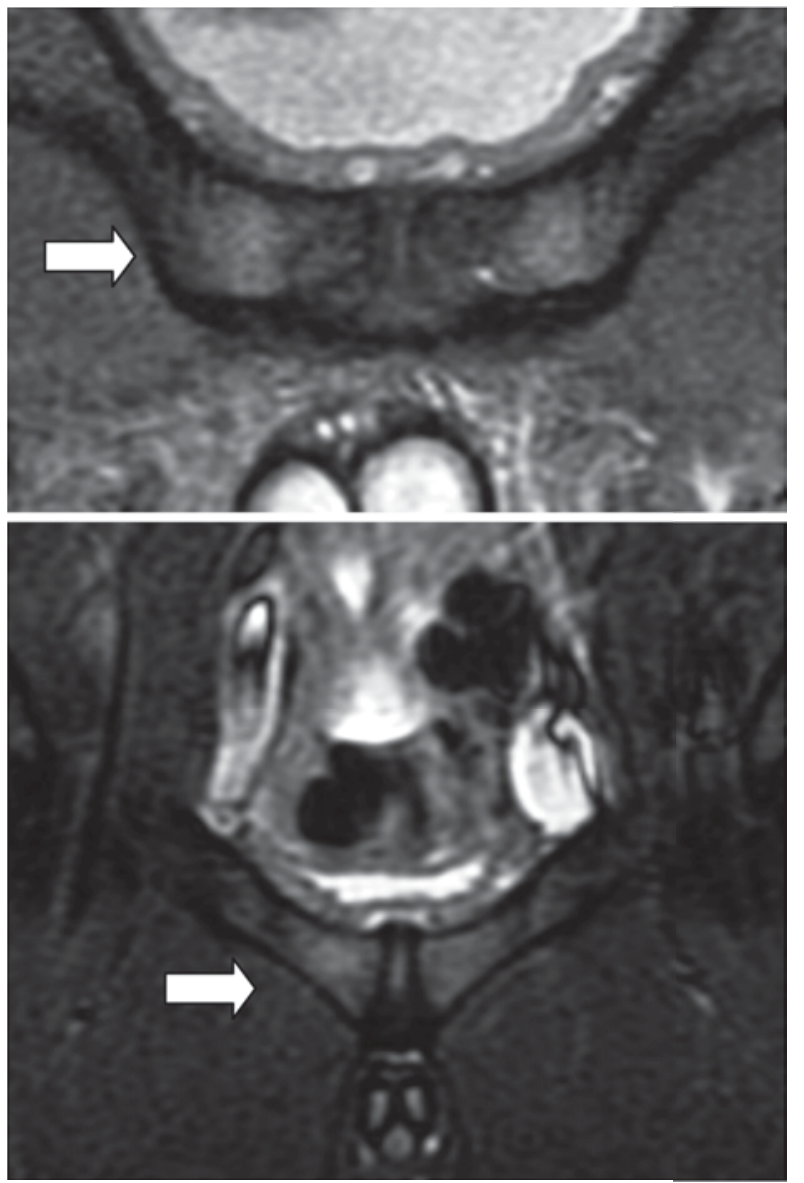

Figura 2 - Imagem de ressonância nuclear magnética de púbis de atleta praticante de futebol a nível competitivo mostrando edema medular (setas), sugerindo osteíte púbica.

atletas assintomáticos ${ }^{(14-16)}$. Embora a prevalência de alterações osteotendíneas observadas na ressonância nuclear magnética em atletas sem queixas prévias seja menor, especula-se que os sinais antes descritos como diagnóstico etiológico da pubalgia são, na verdade, alterações degenerativas relacionadas ao esforço repetitivo.

A sínfise púbica é composta por um disco intra-articular interpondo-se aos dois ossos inominados anteriormente, sendo responsável pela estabilidade anterior do anel pélvico. Não existe cápsula articular. A presença de quatro ligamentos periféricos garante o compartimento articular. A superfície oval é responsável pela transmissão de carga e estabilidade articular. Um pequeno arco
Tabela 2 - Risco de desenvolver alterações degenerativas na sínfise púbica, osteíte ou lesão miotendínea em atletas do sexo masculino praticantes de futebol sob regime intenso e em nível competitívo, comparados com pessoas sedentárias do mesmo sexo, pareados pela idade.

\begin{tabular}{c|c|c|c}
\hline & Risco Relativo & Odds Ratio & p-Valor \\
\hline Alterações Degenerativas & 15,16 & 28,8 & 0,048 \\
\hline Edema (Osteíte) & 5,26 & 7,38 & 0,001 \\
\hline Lesões Miotendíneas & 4,21 & 5,71 & 0,04 \\
\hline
\end{tabular}

de movimento está presente nesta articulação, decomposto em rotação de cerca de $3^{\circ}$ e translação craniocaudal de cerca de $2 \mathrm{~mm}^{(8,9,12)}$.

A área de inserção muscular no ramo púbico é ampla. Os músculos reto abdominal, oblíquos internos e externos e transversos de ambos os lados inserem-se superiormente e agem como estabilizadores dinâmicos do anel pélvico anterior. Inferiormente, os adutores longo, curto e magno, pectíneo e grácil inserem-se na borda do púbis. Medialmente, periféricos à sínfise púbica, os músculos reto abdominal superiormente e adutor longo inferiormente são os principais estabilizadores. Eles agem como um único sistema, gerando vetores opostos, restringindo o movimento desta articulação, prevenindo assim o impacto direto e consequente desgaste do componente cartilaginoso articular. São músculos antagonistas que têm sua ação magnificada durante a marcha ${ }^{(1,7-9,11,12,17)}$.

Seja isoladamente ou associada à osteíte púbica e lesões do reto abdominal, a principal causa de dor na região pubo-inguinal é o acometimento do tendão do músculo adutor longo ${ }^{(18)}$. Alguns autores consideram as patologias como sendo apenas espectros diferentes de uma mesma doença ${ }^{(10)}$, apresentando causa comum, caracterizada pela sobrecarga e esforço excessivo.

$\mathrm{O}$ atleta profissional é submetido a intenso programa de treinamento, além de esforço intenso durante competições. Essa sobrecarga na região púbica pode levar a alterações degenerativas da sínfise. As inserções dos adutores e do músculo reto abdominal podem apresentar lesões devido ao estresse do treinamento. O edema

Tabela 1 - Número de casos e prevalência de alterações degenerativas, incluindo a presença e osteófitos, irregularidade cortical e protrusão discal, edema ósseo representando osteíte púica e lesões miotendinosas. Achados presentes na Ressonância Nuclear Magnética de púbis de atletas e sedentários assintomáticos.

\begin{tabular}{c|c|c|c|c|c|c}
\hline & \multicolumn{2}{|c|}{ Alterações Degenerativas } & \multicolumn{2}{c|}{ Edema (Osteíte) } & \multicolumn{2}{c}{ Lesões Miotendíneas } \\
\hline & Casos & Prevalência & Casos & Prevalência & Casos & Prevalência \\
\hline Atletas & 18 & $94,73 \%$ & 5 & $26,31 \%$ & 6 & $31,57 \%$ \\
\hline Sedentários & 1 & $6,25 \%$ & 1 & $6,25 \%$ & 0 & $0 \%$ \\
\hline
\end{tabular}


ósseo relaciona-se à sobrecarga biomecânica sobre o púbis $^{(9)}$. Essas alterações não estão necessariamente relacionadas à pubalgia. Atletas que passam pelo mesmo treinamento apresentam também tais alterações ${ }^{(10)}$. Até dois terços dos atletas assintomáticos apresentam achados degenerativos na ressonância magnética ${ }^{(10)}$.

Em nosso estudo, comparamos atletas assintomáticos praticantes de futebol profissional com pessoas sedentárias sem história de pubalgia. Observamos uma prevalência significativamente maior de imagens degenerativas nos exames dos atletas do que nos dos não atletas. A prevalência de alterações degenerativas foi de 94,73\% em atletas e 6,25\% em não atletas ( $p=0,048)$.

A prevalência de edema ósseo foi de $31,57 \%$ nos atletas e de 6,25\% nos não atletas, sugerindo que tal alteração relaciona-se provavelmente à sobrecarga púbica ( $p=0,001)$. Alterações de partes moles também foram mais prevalentes nos atletas (26,31\%) comparando-se com não atletas (6,25\%), com $p=0,04$.

Houve um único caso de edema medular ósseo no grupo sedentário. Este voluntário de 23 anos realizava atividade física eventual (corrida e futebol), estando afastado das mesmas há oito meses.

De acordo com os resultados do presente estudo, o atleta profissional de futebol tem risco 15 vezes maior de desenvolver alterações degenerativas na região púbica ao longo de sua carreira, se comparado com não atletas. O risco de o atleta desenvolver osteíte púbica é cinco vezes maior e o de lesões miotendíneas é quatro vezes maior do que em indivíduos sedentários. Alterações degenerativas no púbis têm 28 vezes mais chance de ocorrer em atletas que em sedentários. Já o edema medular ósseo nessa região tem sete vezes e lesões miotendíneas cinco vezes mais chance de ocorrer em atletas que em não atletas.

Nosso estudo apresenta como limitações o número reduzido de atletas e de indivíduos assintomáticos, a ausência de imagens comparativas dos mesmos atletas em diferentes fases de treinamento e a diferença de idade entre os grupos de atletas e sedentários. Quanto a esta diferença de idade, a consideramos favorável, uma vez que o indivíduo sedentário mais idoso estaria submetido a maior estresse, teoricamente; porém, não podemos comprovar este fato.

\section{CONCLUSÃO}

Segundo o presente estudo, atletas profissionais de futebol apresentam maior risco de desenvolver lesões degenerativas, edema medular ósseo e alterações tendinosas na região púbica, se comparados a indivíduos sedentários. Estes achados não são obrigatoriamente causa de pubalgia, estando provavelmente relacionados a esforço intenso.

\section{REFERÊNCIAS}

1. Cunningham PM, Brennan D, O'Connell M, MacMahon P, O'Neill P, Eustace S. Patterns of bone and soft-tissue injury at the symphysis pubis in soccer players: observations at MRI. AJR Am J Roentgenol. 2007;188(3):W291-6.

2. Biedert RM, Warnke K Meyer SS. Symphysis syndrome in athletes: surgical treatment for chronic lower abdominal, groin, and adductor pain in athletes. Clin J Sport Med. 2003;13(5):278-84.

3. Koulouris G. Imaging review of groin pain in elite athletes: an anatomic approach to imaging findings. AJR Am J Roentgenol. 2008;191(4):962-72.

4. Omar IM, Zoga AC, Kavanagh EC, Koulouris G, Bergin D, Gopez AG, et al. Athletic pubalgia and "sports hernia": optimal MR imaging technique and findings. Radiographics. 2008;28(5):1415-38.

5. Lovell G, Galloway H, Hopkins W, Harvey A. Osteitis pubis and assessment of bone marrow edema at the pubic symphysis with MRI in an elite junior male soccer squad. Clin J Sport Med. 2006;16(2):117-22.

6. Brown RA, Mascia A, Kinnear DG, Lacroix V, Feldman L, Mulder DS. An 18-year review of sports groin injuries in the elite hockey player: clinical presentation, new diagnostic imaging, treatment, and results. Clin J Sport Med. 2008;18(3):221-6.

7. Zajick DC, Zoga AC, Omar IM, Meyers WC. Spectrum of MRI findings in clinical athletic pubalgia. Semin Musculoskelet Radiol. 2008;12(1):3-12.

8. Robinson P, Salehi F, Grainger A, Clemence M, Schilders E, O'Connor P, et al. Cadaveric and MRI study of the musculotendinous contributions to the capsule of the symphysis pubis. AJR Am J Roentgenol. 2007;188(5):W440-5.

9. Johnson R. Osteitis púbis. Curr Sports Med Rep. 2003;2(2):98-102.

10. Paajanen $\mathrm{H}$, Hermunen $\mathrm{H}$, Karonen J. Pubic magnetic resonance imaging

findings in surgically and conservatively treated athletes with osteitis pubis compared to asymptomatic athletes during heavy training. Am J Sport Med. 2008;36(1):117-21.

11. Zoga AC, Kavanagh EC, Omar IM, Morrison WB, Koulouris G, Lopez H, et al. Athletic pubalgia and the "sports hernia": MR imaging findings. Radiology. 2008;247(3):797-807.

12. Brennan D, O'Connell MJ, Ryan M, Cunningham P, Taylor D, Cronin C, et al. Secondary cleft sign as a marker of injury in athletes with groin pain: MR image appearance and interpretation. Radiology. 2005;235(1):162-7.

13. Verrall GM, Slavotinek JP, Fon GT. Incidence of pubic bone marrow oede$\mathrm{ma}$ in Australan rules football players: relation to groin pain. $\mathrm{Br} \mathrm{J}$ Sport Med. 2001;28(1):11-9.

14. Brukner P, Cowan S, Crossley K, Schache, A. and Smith, P. Is there a role for magnetic resonance imaging in chronic groin pain? Aust J Sci Med Sport. 2004;7(4 Suppl 1):76.

15. Albers SL, Spritzer CE, Garrett WE Jr, Meyers WC. MR findings in athleteswith pubalgia. Skeletal Radiol. 2001;30(5):270-1.

16. Robinson P, Barron DA, Parsons W, Grainger AJ, Schilders EM, O'Connor PJ. Adductor related groin pain in athletes: correlation of MR imaging with clinical findings. Skeletal Radiol. 2004;33(8):451-7.

17. Cunningham PM, Brennan D, O'Connell M, MacMahon P, O'Neill P, Eustace S. Patterns of bone and soft-tissue Injury at the symphysis pubis in soccer players: observations at MRI. AJR Am J Roentgenol. 2007;188(3):W291-6.

18. O'Connell MJ, Powell T, McCaffrey NM, O'Connell D, Eustace SJ. Symphyseal cleft injection in the diagnosis and treatment of osteitis pubis in athletes. AJR Am J Roentgenol. 2002;179(4):955-9. 